\title{
POTENTIAL EXPLOITATION OF Eucalyptus AND Pinus SOILS AS \\ ALTERNATE SOURCES OF NURSERY MEDIA IN TEA - AN \\ EXAMPLE OF SUSTAINABLE NATURALRESOURCE MANAGEMENT.
}

\author{
K M Mohotti', K G G R Rohan'2, U A Karunanayake ${ }^{3}$ and K Athukorale ${ }^{2}$ \\ TTea Research Institute of Sri Lanka, 2 Sabaragamuwa University, \\ 3Watawala Plantations Limited
}

Tea nurseries require large amounts of soils to cater the plant requirement for now planting, replanting and infilling. Conventionally, soils from natural forests and Mana (Cymbopogon confertiflorus) lands are being used. At present, land use laws, population increase, housing and diversification etc. make these soils scarce in both plantation and small holder sectors. Therefore, this study explored the potentials of Eucalyptus, Pinus and old tea soils as alternative nursery soil resources found in the proximity of tea areas and also known to have caused environmental degradation.

Eucalyptus and Pinus soils were significantly deficient in organic matter, $\mathrm{N}$ and $\mathrm{C}: \mathrm{N}$ ratio compared to that of forest, Mana and old tea soils. All soil sources possessed favourable soil physical properties and $\mathrm{pH}$ levels for tea propagation but no plant pathogenic nematode populations.

Callus formation in Eucalyptus and Pinus soils was similar to forest soils which was significantly greater than that of Mana and old tea soils. Interestingly, Pinus soils exhibited early callusing; forest soils lead longer and greater root biomass of nursery tea plants followed by Eucalyptus and Pinus soils.

Therefore, these results confirmed the potentials of harnessing Eucalyptus and Pinus soils as alternative sources for tea propagation owing to solve the practical limitations with use of forest and Mana soils as well as possible dissemination of soil borne pathogens with use of old tea soils. The study also opens avenues for maximizing utilization of natural resources of introduced plantation forcsts in the vicinity of tea growing areas for agricultural purposes.

Attributes for early callusing and root growth observed with Eucalyptus and Pinus soils are being investigated at present. Studies on overall nursery performance of tea, cost benefit and environmental impact assessments due to large-scale use of such soils are also undenvay for further confirmation.

Proceedings of the Ninth Annual Forestry and Environment Symposium 2003 of the Department of Forestry and Environmental Science, University of Sri Jayewardenepura. Sri Lanka 